\title{
Brote de Fiebre Hemorrágica por el virus del Ébola en Uganda
}

\author{
Aríñez Fernández $\mathrm{M}^{\mathrm{a} C} .^{1}$
}

Sanid. mil. 2012; 68 (1): 33-35; ISSN: 1887-8571

\section{RESUMEN}

En Uganda se está llevando a cabo la Misión de la Unión Europea (EUTM) Somalia, en la que participan efectivos de las Fuerzas Armadas españolas. En mayo de 2011 el Ministerio de Sanidad de Uganda notificó un brote de fiebre hemorrágica por el virus del bola a 70 km de distancia de Kampala. El caso índice y único caso confirmado, fue una niña de 12 años que falleció. La investigación epidemiológica se llevó a cabo por un equipo internacional que incluyó personal del Ministerio de Sanidad de Uganda y de la OMS. Tras mantener la vigilancia del brote durante un tiempo igual a dos veces el periodo de incubación y no confirmar otros casos, fue declarado finalizado el brote el 17 de junio de 2011. Se distribuyó información sobre el brote y recomendaciones de actuación tanto a profesionales de la salud como a la población general.

PALABRAS CLAVE: Fiebre hemorrágica Ébola, Uganda, Brote.

\section{Hemorrhagic Fever outbreak due to Ebola virus in Uganda SUMMARY}

The European Mission (EUTM) Somalia is being conducted in Uganda. Military personnel of the Spanish Armed Forces participate in that mission. On 13 May 2011, The Ministry of Health of Uganda notified a case of Ebola hemorrhagic fever in a district 70 kilometers far from Kampala. The index case and only confirmed case, was a 12-year-old girl who finally died. Epidemiologic surveillance was conducted by an international team including representatives of the Ugandan Ministry of Health and WHO. The Ministry of Health of Uganda declared the end of the outbreak on the 17 June 2011, since the epidemiological investigations, including twofold the incubation period surveillance, did not confirm new cases. Guidelines to control the outbreak and information on the disease were distributed to health professionals and general population.

KEY WORDS: Hemorragic fever Ebola, Uganda, Outbreak.

\section{INTRODUCCIÓN}

La fiebre hemorrágica por el virus del Ébola es una infección grave causada por un virus del género Ebolavirus, de la familia Filoviridae. El virus se aisló por primera vez en 1976 tras un brote de fiebre hemorrágica ocurrido en Zaire y Sudán en el que fallecieron 250 personas $^{1,2}$. Por el momento se han identificado tres especies distintas de Ebolavirus: Zaire, Sudán, Côte d'Ivoire y Bundibugyo con afección de los seres humanos. Un cuarto subtipo de Ebolavirus, el de Reston, causa un cuadro hemorrágico mortal en primates no humanos originarios de Filipinas, y aunque se han diagnosticado pocas infecciones por este virus en personas, fueron cuadros asintomáticos.

Hasta la fecha se desconoce el reservorio. En África se han aislado infecciones por el virus del Ébola en gorilas, chimpancés, simios antílopes selváticos, puerco espines y murciélagos ${ }^{3}$. La infección en humanos por el virus de Ébola se produce probablemente por contacto directo con sangre y secreciones infectadas ${ }^{4}$. La transmisión por vía inhalatoria en condiciones naturales no ha sido demostrada. El máximo riesgo es durante las etapas tardías de la enfermedad, cuando el enfermo vomita, tiene diarrea o sangra y durante los fu-

${ }^{1}$ Cte. Médico. Cuartel General del EUROCUERPO, Estrasburgo, Francia.

Dirección para correspondencia: arinezmc@gmail.com

Recibido: 30 de noviembre de 2011

Aceptado: 12 de diciembre de 2012 nerales, durante la manipulación de los cadáveres sin protección. El riesgo durante el periodo de incubación es bajo.

El periodo de incubación es de 1 a 21 días, tras el que aparece de forma repentina fiebre, malestar, mialgias y cefalea, seguidas de faringitis, vómito, diarrea y erupción maculopapulosa. En los casos graves y mortales, la diátesis hemorrágica se acompaña de lesión hepática, insuficiencia renal, afección del sistema nervioso central y shock, con disfunción multiorgánica. Las tasas de letalidad varían entre 50\% a 90\%. En Uganda se declararon dos brotes anteriores de fiebre hemorrágica por virus de ébola en el año 2000 y en $2007^{5,6}$.

\section{DESCRIPCIÓN DEL CASO}

El 13 de mayo de 2011, el Ministerio de Salud de Uganda notificó a la Organización Mundial de la Salud (OMS) un caso de fiebre hemorrágica de Ébola en una niña de 12 años de la aldea de Nakisamata, parroquia de Ngalonkalu, subcondado de Zirobwe del distrito de Luwero, en el centro del país, a 70 kilómetros de Kampala ${ }^{7-9}$.

El 6 de mayo visitó una clínica privada de la ciudad de Zirobwe con antecedentes de enfermedad febril aguda de 6 días de evolución y manifestaciones hemorrágicas. Posteriormente fue derivada al Hospital Militar General de Bombo, donde falleció a las pocas horas del ingreso.

Se realizaron pruebas diagnósticas de laboratorio, detección de IgM por medio de ELISA y PCR, en el Instituto de Investigaciones Virológicas de Uganda (Entebbe, Uganda). El resultado fue positi- 
vo, lo que confirmó la infección por virus del Ébola (especie Sudán). Además, se envió una muestra a los Centros para la Prevención y el Control de Enfermedades (CDC) de los EE.UU., en Atlanta, para ser sometida a otros análisis y a una secuenciación génica ${ }^{7,9}$. Fue el único caso confirmado por laboratorio.

La respuesta a este brote fue coordinada por un grupo de trabajo internacional que incluyó a representantes del Ministerio de Sanidad de Uganda, de la OMS, CDC, la Red Africana de Epidemiología de Campo (AFENET) y la Agencia para el Desarrollo Internacional de los Estados Unidos (USAID) 7,9 .

El gobierno ugandés, la OMS y los otros colaboradores establecieron un sistema de vigilancia epidemiológica activa con el fin de detectar los casos y realizar el seguimiento de los contactos. Se llevaron a cabo reuniones semanales y diarias de subgrupos de trabajo con la emisión final de un Informe de Situación que recogía la evolución del brote, las actividades realizadas de control y preventivas y las recomendaciones dadas a los profesionales sanitarios y a la población general ${ }^{8}$. La OMS no recomendó en ningún momento que se impusieran a Uganda restricciones a los viajes ni al comercio ${ }^{7,9}$.

Se llevó a cabo un estudio de contactos que incluyó a 25 personas en contacto estrecho con el caso índice y que fueron seguidas hasta el día 27 de mayo de 2011 sin que ninguna de ellas manifestaran síntomas de haber contraído la enfermedad. Los casos sospechosos se aislaron en diversos hospitales de la zona como Mulago, Bombo y Nakaseke ${ }^{9,10}$.

Además, fueron investigados 13 casos con 3 muertes entre los casos alertados y 20 casos con 6 muertes entre los casos sospechosos originarios de Kampala, Wakiso, Luwero, Bugiri, Kasese, Nakasese, Kabale y el distrito de Gulu, todos ellos con un resultado negativo de infección por virus de Ébola, Marburg y fiebre amarilla ${ }^{10}$.

Un equipo de los CDC llegó el 17 de mayo 2011 a la parroquia de Ngalonkalu. Realizaron estudios ecológicos con el fin de conocer la fuente de infección que incluyeron la investigación de muestras de sangre de 50 murciélagos frugívoros, 14 murciélagos insectívo-

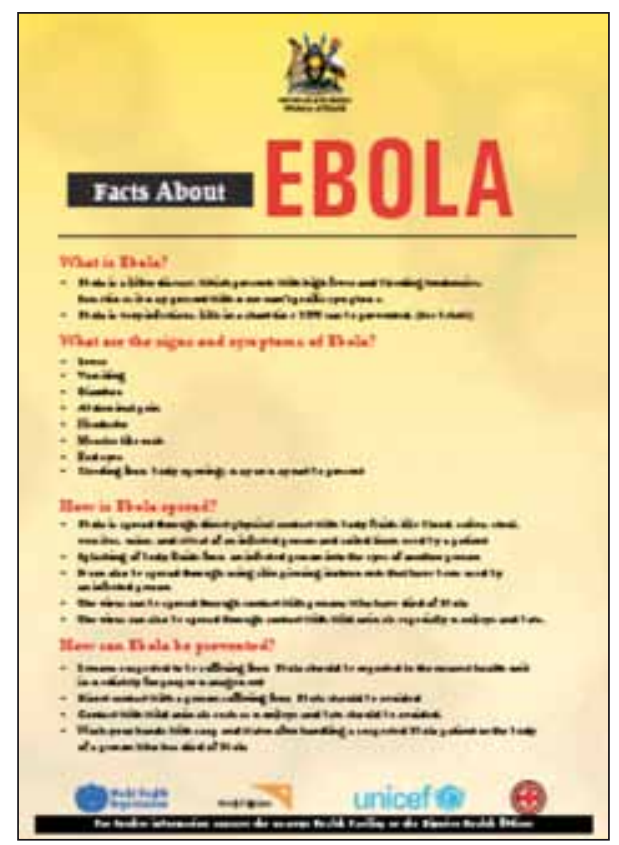

Figura 1. Poster informativo sobre la fiebre hemorrágica por virus del Ébola en inglés. ros y una muestra de heces de un mono con resultados todos negativos para los virus de ébola y Marburg ${ }^{10}$.

Al mismo tiempo se reforzó la vigilancia epidemiológica en todo el país con el fin de seguir la posible diseminación del virus y revisar la definición de caso. Además, se estableció una línea telefónica nacional y local de alertas para facilitar la notificación de cualquier caso sospechoso. Se reactivó una página web como apoyo a la diseminación de la información al personal sanitario y a la población general ${ }^{8,10}$.

Se proporcionó apoyo psicológico a la familia del caso índice y a las familias del vecindario con ayuda de Médicos sin Fronteras (MSF) España ${ }^{10}$.

Se alertó a los almacenes nacionales proveedores de medicamentos, National Medical Stores, para proporcionar medicamentos de forma urgente ${ }^{10}$.

El Ministerio de Sanidad de Uganda estableció un plan de respuesta con una financiación de 3.632 billones de Ugandan Schillings para facilitar la movilización de recursos gubernamentales y de empresas sanitarias. UNICEF contribuyó aportando aproximadamente $2.000 \$$ para la compra de material de protección individual como batas, guantes, sábanas de plástico, bidones de agua y botas de goma. AFENET y empresas privadas en el país financiaron la emisión de información radiofónica en todo el país sobre la evolución del brote. Distintas organizaciones como OMS, CDC y MSF proporcionaron apoyo con equipos de protección individual a los hospitales donde se efectuaba el aislamiento de los contactos ${ }^{10}$.

Se distribuyó material gráfico, como posters, trípticos y folletos, con información en inglés y swahili (Figura 1 y 2) y Recomendaciones para el Control de la Fiebre de Ébola en la Comunidad (Figura 3). Al mismo tiempo, se informó regularmente a los medios de comunicación con notas y ruedas de prensa sobre la evolución del brote $^{8,10,11}$.

Pasados 42 días de la declaración del brote, y tras una vigilancia epidemiológica estrecha de los contactos sospechosos en los que no se confirmó ningún otro caso, el Ministerio de Sanidad de Uganda

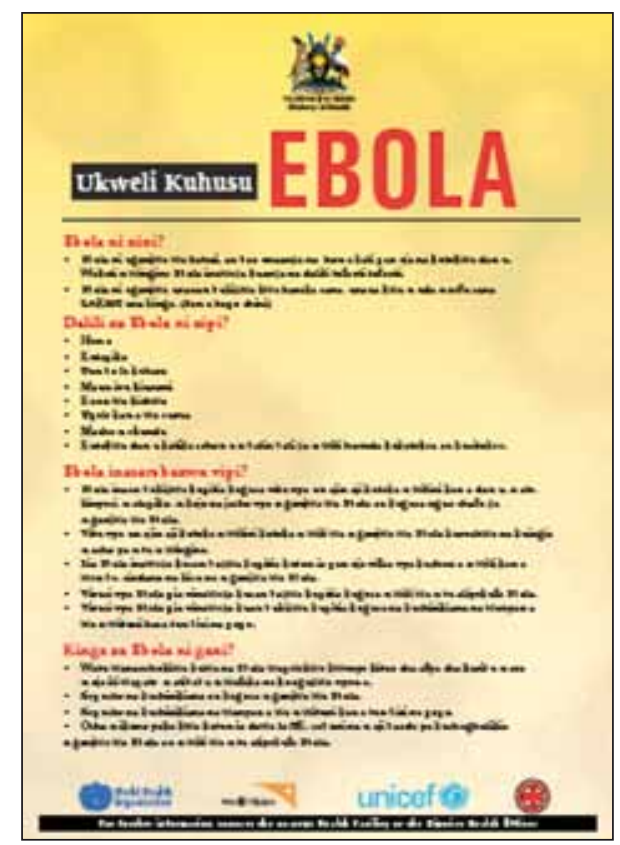

Figura 2. Poster informativo sobre la fiebre hemorrágica por virus del Ébola en swahili. 


\section{Brote de Fiebre Hemorrágica por el virus del Ébola en Uganda}

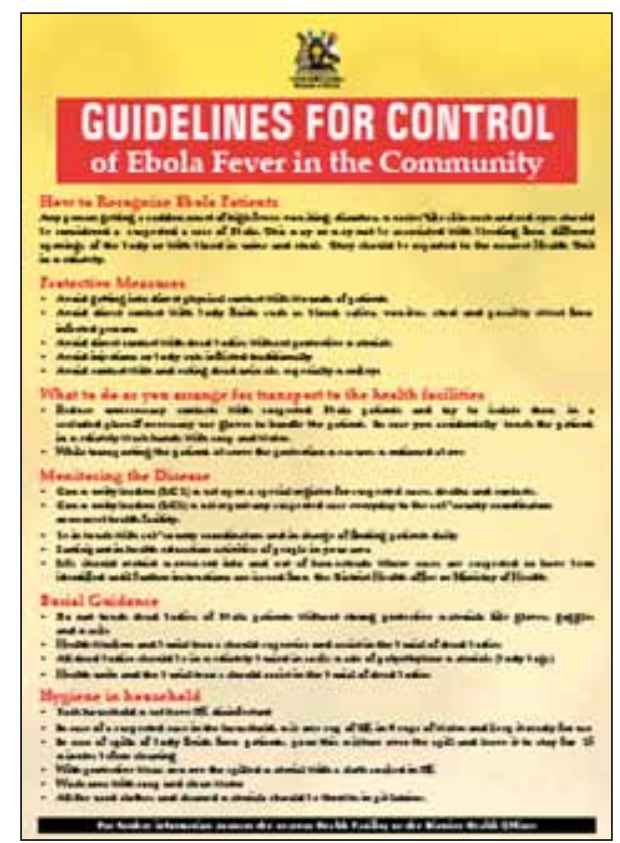

Figura 3. Recomendaciones para el control de la fiebre por virus del ébola en la comunidad.

declaró terminado el brote el 17 de junio de 2011. Esta información se proporcionó a los profesionales de la salud y a la población general mediante comunicados en prensa escrita en los periódicos mayoritarios del país ${ }^{12}$.

El Medical Advisor de la Operación EUTM Somalia contactó con los responsables del Departamento de Control de Enfermedades Transmisibles de la Oficina de la OMS en Kampala y fue incluido en la lista de distribución por correo electrónico del Informe de Situación del Grupo de Trabajo, de tal forma, que estaba constantemente informado de la evolución del brote y de las recomendaciones oficiales. Los Informes de Situación fueron enviados al Mando de Operaciones (MOPS), Instituto de Medicina Preventiva de la Defensa (IMPDEF) y a la Inspección General de Sanidad con el fin de informar de la evolución del brote y de las recomendaciones específicas que pudieran afectar a los efectivos de nuestras Fuerzas Armadas (FAS) y multinacionales desplegados en zona de operaciones.

El IMPDEF elaboró un informe dirigido a CMOPS con las normas de actuación que sería preciso conocer en el caso de que se pro- dujeran casos de la enfermedad en los despliegues de nuestras FAS y publicó una monografía sobre la infección por el virus del Ébola y las medidas de prevención y control en el Boletín Epidemiológico del IMPDEF del mes de abril de 2011.

Siguiendo las recomendaciones de la $\mathrm{OMS}^{7}$, no se impusieron restricciones de movimiento en el país a los efectivos españoles desplegados $^{8}$.

En Uganda se declararon dos brotes anteriores de fiebre hemorrágica por virus de ébola en el año 2000 y en $2007^{5,6}$.

Como conclusión en relación con el despliegue de efectivos militares en zona de operaciones, se resalta el hecho de que el contacto directo del Asesor Médico de una operación con la Oficina de la OMS situada en el país donde están desplegados los efectivos de las FAS o multinacionales es una fuente para obtener información fidedigna de la evolución de brotes y de las recomendaciones específicas de actuación para la prevención y control de las enfermedades que puedan poner en riesgo a los efectivos militares desplegados.

\section{BIBLIOGRAFÍA}

1. Ebola hemorrhagic fever in Sudan, 1976. Report of a WHO/International Study Team. Bull World Health Organ. 1978;56:247-70.

2. Ebola hemorrhagic fever in Zaire, 1976. Bull World Health Organ. 1978;56:27193.

3. Pourrut X, Souris M, Towner JS, Rollin PE, Nichol ST, Gonzalez JP, Large serological survey showing co-circulation of Ebola and Marburg viruses in Gabonese bat populations, and a high seroprevalence of both viruses in Rousettus aegyptiacus. BMC Infect Dis. 2009;9:159.

4. Francesconi P, Yoti Z, Declich S, Onek PA, Fabiani M, Olango J, et al. Ebola hemorrhagic fever transmission and risk factors of contacts, Uganda. Emerg Infect Dis. 2003;9:1430-7.

5. The Uganda Ebola outbreak - not all negative. Bulletin of the World Health Organization, 2000, 78 (12)

6. Ebola haemorrhagic fever, Uganda - end of the outbreak. WER, 2008, 83, 89-96.

7. Ebola in Uganda. Who Global Alert and Response. http://www.who.int/csr/ don/2011_05_18/en/index.html

8. Ebola Uganda, WER 2011, 22, 86, 221-232. http://www.who.int/wer

9. Ebola Hemorragic Fever - Uganda, Archive number: 20110617.1856. www.promedmail.org

10. Ebola outbreak in Uganda. National Task Force Situation Report (Sitrep No 12) $1^{\text {st }}$ June2011.

11. Página web del Ministerio de Sanidad de Uganda. www.diseaseoutbreaks.ug

12. Uganda declared Ebola-free again. Daily Monitor. 2011June20. Accesible en http://www.monitor.co.ug/News/National/-/688334/1185424/-/c09be9z/-/index. html 